which have been chronic, giving rise to continued diarrhoea, often with blood and mucus in the stools, and proving refiactory to ordinary methods of treatment. These cases have been regarded as not due to bacillary or amoebic dysentery, but precise evidence as to the absence of the former is usually lacking. The present series of cases is complicated by the fact that, in the majority of them, one or more types of pathogenic bacteria have been obtained. Blood, mueus, and pus stools have occurred only in two cases, from both of which Shiga's bacillus was recovered. On other occasions, where loose stools have occurred, at times slightly mucoid but with no blood or pus, Shiga has either been obtained or, where not actnally recorered, the patient's serum has subsequently given the agglutination reaction. Or, again, some other organism-for example, B. paratyphosus $\mathrm{A}$-has been present. In several cases, in fact, the patients appear to have been infected with several different organisms, bacteria and protozoa. It is quite possible that the bacteriat infection and the disturbance cansed by it have favoured the establishment of the protozoan infection, whaterer this has been.

Nevertheless, there is a residuum of cases, where loose diarrhoeal stools have occurred, containing flagellates or their cysts, where no evidence of pathogenic bacteria has been obtained. Where actire flagellates are present the motions are nearly always loose or thin and creamy or bright yellow in colour, the latter being markedly the case with stools containing Trichomonas. This parasite las occurred in diarrhoeal stools from one patient at intervals over eighteen days, after which it apparently died out. Cp to the present this form lhas not proved persistent or refractory. Lamblia is probably a more important canse of intestinal derangement, and this can be readily under. stood when the essential parasitic character of this form and the situation it occupies are borne in mind. The following is the record of one of three very similar cases of infection with this parasite, uncomplicated (now) by the presence of any other pathogenic organism. In the instance in question, the active forms liare nerer been seen in the stools examined; this fact shows the impor. tance of the recognition of the cysts.

W-s. Admitted September 26th, 1915.

September 28th. Pasty vellow stool; fair number of $L$ amblia crsts.

October 13th. Loose, slightly mucoid stool; no blood or pus; some Lamblia cysts.

October 22nd. Pasty, olive-green stool; very numerous I.amblia cysts.

October 30th. Thin, soup-like, greenish-brown stool; no blood or mucus ; numerous Lamblia cysts.

The presence of cysts in such numbers indicates, of course, a heavy intestinal infection with the actire forms: During this period the patient has snffered from olhronic diarrhoea; during the night before the last sample was examined, for instance, he had five thin or loose motions. Prior to admission, the patient, who came from Gallipoli, had a history of six weelss' dysentery and diarrhoea, with blood and mueus in the stools during the first two or three weelss. During this early period he had three or four injections of emetine. Probably, therefore, the patient had amoebic dysentery, which was entireiy cured by the emetine, for neither Entamoebae nor their cysts have ever been found in the stools. The emetine had apparently, lowever, no effect upon the Iiamblia. French workers strongly recommend turpentine (térébenthine) in cases of persistent diarrhoea due to these flagellates. It is hoped to obtain further information upon this subject as time goes on.

Ledingham RFFrRENCES.

1 Ledingham and Arkwright: The Carvier Problem in Infectious Discase (Ânold), 1912. 2 Wien. klin. Woch., 1915, pp. 579, 620.

ACConding to the New York Medical Record, the fleld service of the American Ambulance in Paris during the first eleven months of its activity transported 57,000 wounded from the front. The number of automobiles now employed in this service is about ninetr, and, in addition, twenty machines are attached to the hospital at Neuilly. One supply and one staff machine accompany each of the units in the fleld, themselves composed of from ten to twenty-flve cars. There have been no deaths among the drivers of the fleld ambulance, although ther go very near to the fighting lines and are trequently under heavy fire. More cars are added to the freld eqtripment as the fund srows. The number of beds in the hospital at Nejilly has been increased from 175 to 600 .
NO'L ON TIE TETRITAC'INE: TYPIIOID + PARATYPHOID A + PARATYPHOID B + CHOLERA.

BY

Professor aldo Castellayi, M.D.

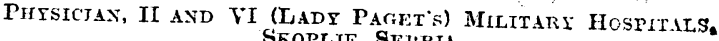
SKOPIJE, SElibia,

AND

RALPH W. MENDELSON, M.D., Mlember of the American RFp Cross Savitatic Comulssion,

Ir may be of interest to put on record the somcivhat extensive experience we have had in Serbia with the tetravaccine: typhoid + paratyphoid $\mathbf{A}+$ paratyphoid $\mathbf{B}$ tcholera, one of the combined vaccives prepared and used for several years in Ceylon by one of us.

\section{Technique of Preparation.}

This is identical with that used by onc of ns previously, and already pnblisted in varions papers. It may, how. ever, be of advantage to describe it again briefly.

The growth of typhoid cultures is waslied off withi sterile 0.85 per cent. salt solution, to which 0.5 per cent. carbolic acicl has been added; the emulsion so obtained is stored at room temperature $\left(18^{\circ}\right.$ to $20^{\circ} \mathrm{C}$.) for trentyhours, and then standardized. To standardize it the germs are counted by using a Thoma-Zeiss apparatus, and sufficient carbolic salt solution is added to bring the number of gernis down to 2,000 millions per cubic centi. metre. The standardized emulsion is tested for sterility. The same procedure is carried ont with paratyphoid A aud paratyphoid $B$ cultures, these two emulsions being also standardized to contain 1,000 million germs per cubic centimetre. The above procedure is also carried ont with cholera, the emulsion of which, however, is standardized to contain 4,000 million germs per cubic centimetre. The four standardized emulsions wlicn found sterile are mixed together in equal proportions, and the raccine will therefore contain per cubic centimetre:

Typhoid

Paratyphoid A

Clrolera

$$
\begin{aligned}
& 500 \text { million } \\
& 250 \quad, . \\
& 250 \quad " . \\
& 1,000 \quad . .
\end{aligned}
$$

Of this mixture 0.5 to 0.6 e.cm. are given moder the skin of the arm the first time, and the same amonut a week later. A third dose, also $\frac{1}{3}$ c.cm., giren two weels after the-first, is of adtantage, but not essential for practical purposes.

The Peptone Water Method.-Owing to the scarcity of agar at one time in our laboratory we prepared a cerbain amount of vaccine with peptone water in the following way. Large bottles were filled with peptone water containing 1 per cent. peptone and 0.75 per eent. sodium chloride, and sterilized. Some of the bottles were then inoculated with typhoid, others with paratyphoid $A$, others with paratyphoid B, and others with cholera. The cholera bottles are kept in the incubator at $35^{\circ} \mathrm{C}$. for twenty-four hours. The bottles inoculated with typhoid, paratyphoid A, and paratyphoid $B$ were incubated for forty-eight hours, as the growth of B. typhosus and allied germs is slow and scanty in such a medium. We found by experience that with the peptone water we used and with the strains of germs we had, provided the bottles were kept in the incubator exactly the stated period of time and temperature, the number of germs was, for practical purposes, nearly constant. The cholera bottles will contain approximately 3,800 to 4,000 million cholera ribrios per cubic centimetre and the typhoid and paratyphoid bottles will contain approximately 900 to 1,000 million per cubic centimetre. The peptone water cultures were then mixed in the following proportions:

Trphoid

Paratyphoid A

Cholera ...

$$
\begin{array}{llll}
\ldots & \ldots & \ldots & 2 \text { parts } \\
\ldots & \ldots & \ldots & 1 \text { part } \\
\ldots & \ldots & \ldots & 1 \text { part }
\end{array}
$$

T, this was added $\frac{i}{2}$ per cent. catbolic, which is sufficient to sterilize tlice raccine in a rery few hours. We may say at once that the results obtained with this vaccine as regards agglutinins, etc., appear to ke very 
similar to those obtained with the carbolized agar culture vaccine, though whenerer possible re prefer to use the latter.

Experimental Work on which the Freparation of the Tetravaccine and other Mixed Vaccines is Based.

The preparation of tetravaccine, as well as other combined vaccines, is based on the experimental work of one of us carried out in 1901 and 1902,12 when it was demon. strated that if an animal (rabbit) was inoculated with two or three species of bacteria, agglutinins and immune bodies for all the germs were elaborated, provided a sufficient minimum quanity was given, the amount of agglutinins and immune bodies elaborated for each germ being nearly the same as in control bodies inoculated with only one species. It was also demonstrated that when immunization is obtained by a single inoculation, the amount of agglutinins and immune bodies elaborated is not in proportion to the amount of culture injected, provided a sufficient minimum dose be used. A series of rabbits inoculated with 2 c.cm. of typhoid culture gave the same average agglutination limit and the same amount of immune bodies as a series of rabbits inoculated with 4 c.cm. In rabbits no good results were obtained, as a rule, by inoculating more than three species of bacteria.

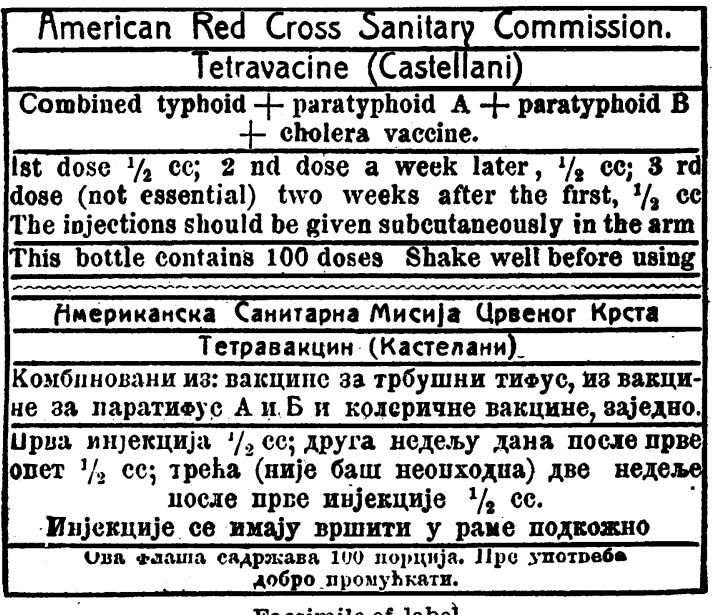

But more recent experiments have shown that in rabbits the tetravaccine-typhoid, paratyphoid A, paratyphoid $B$, and cholera, induces protective substances for the four germs in the rabbit.

\section{Blood Examination of Rablits Inoculated with the} Tetravaccine.

The particulars of the investigation will be given in a future more complete paper. Here we will limit ourselves to the statement that according to our researches the blood of the inoculated rabbits developed agglutinins for the four germs, and that the amount of agglutinin developed for each germ was not distinctly less than in rabbits inoculated with monovaccines. Porcelli, using Castellani's tetravaccine, has come to the same conclusion. ${ }^{3}$

\section{Number of Individuals Inoculated and Technique of} Inoculation.

The number of individuals inoculated by us with the tetravaccine amounts to 50,000 , and more than 120,000 by colleagues, among whom we would like to mention Colonel Randon, who has very ably organized such vaccination for the civil population, also on a very large scale, and Dr. Boricks, who has now started the preparation of the tetravaccine at the Government Pasteur Institute of Nish. The method for preparing the arm for inoculation was simple. At first we took elaborate means to scrub the arm thoroughly with soap and water, drying, and then painting with tincture of iodine; but when inoculating at the rate of several thousand a day, we found it impossible to spend the time necessary for this procedure, and depended entirely upon the iodine alone, with excellent results.

The reactions were usually very mild and consisted usually of a small area of redness, a slight local temperature and some tenderness. Goneral reactions were very seldom complained of, and when inquired into revealed a slight headache and a general inaptitude. These particulars were carefully looked into in all cases upon the second inoculation.

It seems hardly permissible to elaborate upon the technique of inoculation, yet with continued practice one acquired a skill that almost assumes the dignity of an art. We have found it possible when everything is going right to inoculate at the rate of 400 an hour. The left arm is chosen, the skin over the insertion of the deltoid, and a quick stab, as though one were shaking a drop of ink from a pen, results in placing the point of the needle at the exact depth. The syringe is held in the right hand between thumb and index finger, while the tip of the ring finger is placed just above the point of the needle, acting as a check to the force applied. No after-treatment such as massage or sealing the puncture is used.

\section{Blood Examination of Individuals Inoculated with the} Tetravaccine.

We have examined the blood of more than 100 individuals inoculated with the tetravaccine for agglutinins. In ten we studied the agglutination curve for several weelss. We propose giving the particulars with all the tables referring to this subject in a future more complete paper. We aro limited here to giving a table containing the results obtained in three individuals in whom the observations wero carried on for six weeks.

Tetravaccine (Tu' Inoculations : 1 c.cm. first, $\frac{1}{2}$ c.cw. second.)

\begin{tabular}{|c|c|c|c|c|c|c|c|}
\hline \multirow{2}{*}{$\begin{array}{l}\text { Indi- } \\
\text { viduals } \\
\text { Inocu- } \\
\text { lated. }\end{array}$} & \multirow{2}{*}{ Blood tested against } & \multicolumn{6}{|c|}{$\begin{array}{l}\text { Limits of Agglutination. } \\
\text { Weeks after First Inoculation. }\end{array}$} \\
\hline & & 1 & 2 & 3 & .4 & 5 & 6 \\
\hline \multirow{4}{*}{ No. 1} & B. typhosus. & $\mathrm{T} / 20$ & $1 / 1200$ & $1 / 400$ & $1 / 300$ & $1 / 150$ & $1 / 150$ \\
\hline & B. paratyphosus A .... & $1 / 20$ & $\mathrm{I} / 300$ & co & $x / 150$ & $1 / 100$ & $1 / 60$ \\
\hline & B. paratyphosus B... & $\mathrm{I} / 20$ & $\mathrm{~J} / 2 \mathrm{CO}$ & $\pi / 200$ & $1 / 200$ & $1 / 150$ & $\mathrm{x} / 8 \mathrm{O}$ \\
\hline & V. cholevae $\quad \ldots \quad \ldots$ & $\mathrm{I} / \mathrm{so}$ & $1 / 100$ & $1 / 100$ & $1 / 80$ & $1 / 80$ & $1 / 60$ \\
\hline \multirow{4}{*}{ No. 2.} & B. typhosus ... ... & $\mathrm{I} / 4^{\circ}$ & $\mathrm{r} / 800$ & $1 / 300$ & - & $1 / 200$ & $1 / 100$ \\
\hline & B. paratyphosus $\mathrm{A}$... & $\mathrm{I} / 20$ & $1 / 200$ & $1 / 150$ & 一 & $x / 100$ & $1 / 10$ \\
\hline & B. paratyphosus B ... & $1 / 20$ & r/150 & I/too & - & $1 / 80$ & $\mathbf{r} / 4$ \\
\hline & p.encerce $\cdots$ & & $1 / 40$ & & & & $x_{i}$ \\
\hline \multirow{3}{*}{ No. 3.} & B. typhosus ... ... & $1 / 40$ & $1 / 1000$ & $I / 4000$ & $1 / 200$ & I/Ico & $\begin{array}{l}1 / 80 \\
1 / 60\end{array}$ \\
\hline & $\begin{array}{l}\text { B. paratyphosus } \mathbf{A} \\
\text { B. paratyphosus } \mathbf{B}\end{array}$ & $\begin{array}{l}1 / 20 \\
1 / 10\end{array}$ & $\begin{array}{l}1 / 250 \\
1 / 200\end{array}$ & $\begin{array}{l}I / 200 \\
I / 150\end{array}$ & $\begin{array}{l}1 / 150 \\
1 / 150\end{array}$ & $\begin{array}{r}1 / 80 \\
1 / 100\end{array}$ & $\begin{array}{l}1 / 60 \\
1 / 60\end{array}$ \\
\hline & V. cholerae $\quad .$. & $\mathrm{I} / \mathrm{1O}$ & $1 / 100$ & $1 / 40$ & $1 / 20$ & $1 / 30$ & $1 / 20$ \\
\hline
\end{tabular}

The individuals inoculated with the tetravaccine produce a very large amount of agglutinins for typhoid, a fairly large amount of agglutinins for paratyphoid $A$ and paratyphoid $B$, a certain amount for cholera, which varies between the limits $1: 20$ and $1: 150$. Comparing the results with those obtained in control individuals inocu lated with typhoid, paratyphoid $A$, paratyphoid $B$, and cholera, we find that the amount produced is not distinctly smaller: The tables referring to all the cases, including the controls inoculated with monovaccines, will be pub. lished in a later more complete paper.

\section{Statistics.}

We are not in a position now to give any claborate statistics, but we may say that so far, in the inoculated troops, typhoid, paratyphoid A, and paratyplioid $B$ have been practically absent. The very few cases reportedwithout any death-have mostly been proved to be cases of intermittent or remittent subtertian, there being in the country now an extremely severe epidemic of malaria. As regards cholera, no cases have been reported, but the disease is not now present in Serbia.

\section{Conclusions.}

1. The preparation of the tetravaccine (typhoid, para. typhoid A, paratyphoid B, and cholera) as well as other combined vaccines is based on the experimental work carried out by one of us in 1901, when it was demonstrated that animals inoculated with more than one species of bacteria, within limits, developed agglutinins and immuno bodies for all the species injected, the amount of such bodies being not distinctly inferior to that observed in control animals inoculated with one species only.

2. The inoculation of the tetravaccine is harmless. Wo have had no septic or other accident in any of the more than 50,000 men we have inoculated, this entailing more than 100,000 injections, nor have we heard of any untoward 
accident observed by colleagues who have inoculated in Serbia more than 120,000 men with the tetravaccine. . We have never observed any really serious reactions, either local or general, the inoculated persons being as a rule able to attend to their duties in from twenty-four to fortycight hours after injection.

3. The inoculated persons develop protectire substances tor the four germs: typhoid, paratyphoid A, paratyphoid P, and cholera. The amount of agglutinins present for each of the four germs is practically the same as in control individuals inoculated with typhoid, paratyphoid A, paratyphoid B, and cholera monovaccines.

4. We are of the opinion, as stated in previous publica. tions, that the tetravaccine should be used as a matter of rontine to inoculate the troops taking part in the present war', greatly exposed as they are to the four diseases, typhoid, paratyphoid $A$, paratyphoid $B$, and cholera. Its use rendcrs it possible to give a contemporaneous pro tection for the four maladies by a simple and rapid procedure.

As we have already received numerous requests and inquiries from many quarters, and as the time at our disposal makes it impossible for us to supply the vaccine to all who asls for it, it may be mentioned that the tetravaccine is now prepared on a large scale by Mulford and Co., of Philadelphia, and can be obtained from them.

1 Castellani : Ceylon Med. Reports, 1904-1905: Centr, fiir Bakt., 1909 BRTTISH MEDICAL JoURNAI, 1913 (vol. i1, p. 1577, 1914-1915: Jour? Ceylon Branch Britsh Medical Association, June, 1914; Sperimentale, jeriment Mischinfect. 3 Porcolli : Il tetravaccino Castellani, leiforma ulectica, 1915 .

\section{PARATYPHOID "A" FETER. BI}

A. H. SAFFORD, D.P.H.LoND, MAJOR, R.A.M.C.'

Althodin paratyphoid fever has been recognized for several years, and during the last three or four years has become of considerable importance in India, especially as affecting the British troops, it appears soldom to be recognized by civilian practitioners, and not much attention been paid to it outside the army. This is no loubt due to the fact that few textbooks give more than a bricf sketch of the disease.

The following notes are based on over a hundred cases which I have personally observed and in which the Bacillus paratyphosus A was isolated in each instance, cither from the blood, urine, or faeces.

Definition.-A septicaemia caused by the presence of the Bacillus paratyphosus A, causing a remittent type of fever of about twelve days' duration.

Incubation.-From ten to fifteen days.

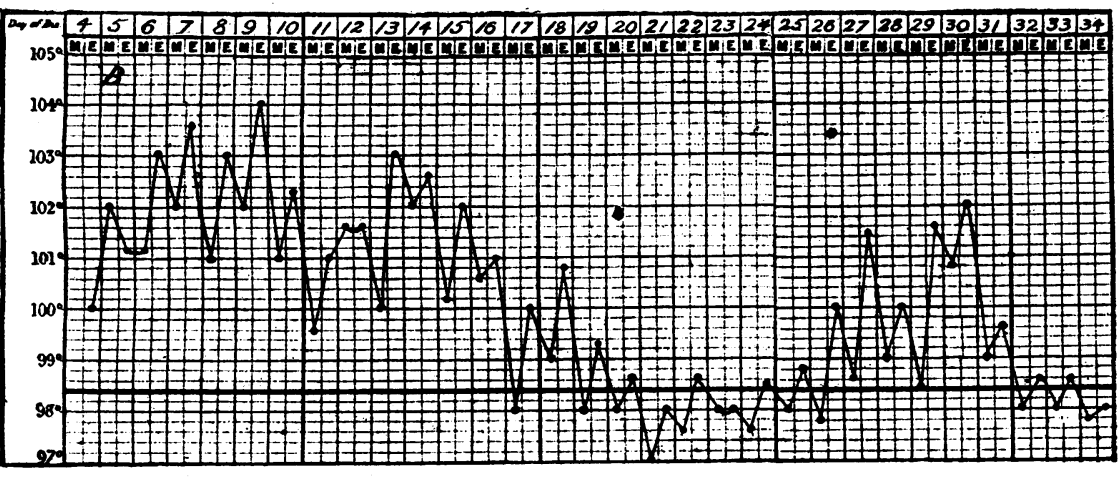

Chart to illustrate a severe case of paratyphoid $\mathbf{A}$ fever followed by a relapse. B, Blood culture positive.

Immunity.

In India race seems to bear no relation to immunity, for although the organism has been more frequently isolated from Europeans than from Indians this is due chiefly to failure in taking the necessary steps for its isolation among the latter. From five blood cultures from Indians I have isolated B.paratyphosus A on two occasions and B. typhosus once. It appears to bo more common among men than women, but no definite statement on this can be made at

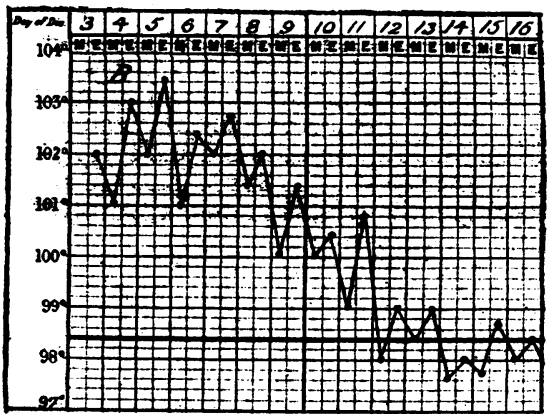

Chart to illustrate a typical case of paratyphoid A fever. B, Blood culture positive.

present owing to the excess of malc over female population in the army in India. One attack protects against a second. I have never seen or heard of a second attack. As might; be expected, antityphoid inoculation gives no protection against paratyphoid.

Bacteriology.

A Gram-negative motile bacillus is present which agglu. tinates with high titre paratyphoid $A$ serum, and by the absorption test can remove tlie agglutinins.

\begin{tabular}{|c|c|c|c|}
\hline & 24 Hours. & 48 Hours. & 10 Days. \\
\hline $\begin{array}{lr}\text { Glucose } & \ldots \\
\text { Lactose } & \ldots \\
\text { Cane sugar } & \\
\text { Mannite } & \ldots \\
\text { Dulcite } & \ldots \\
\text { Inulin } & \ldots \\
\text { Neutral } & \text { red } \\
\text { agar } & \\
\text { Litmus milk } \\
\text { Indol } & \ldots\end{array}$ & \begin{tabular}{|} 
Acid + gas + \\
No chango \\
No chango \\
Acid + gas + \\
No chango \\
No change \\
Gas + fluorescence - \\
Acid + clot - \\
Nil
\end{tabular} & \begin{tabular}{|l} 
Acid + gas + \\
No change \\
No chango \\
Acid + gas + \\
Acid + gas + \\
No change \\
Gas + fluorescence - \\
Acid + clot - \\
Nil
\end{tabular} & $\begin{array}{c}\text { The } \\
\text { same as } \\
\text { after } \\
48 \text { hours' } \\
\text { incuba- } \\
\text { tion. }\end{array}$ \\
\hline
\end{tabular}

Symptoms.

The onset is as a rule insidious, there being a general feeling of lassitude and loss of appetite. There is complaint of headache (frontal ard occipital), pain in the back and limbs, and chills. A rigor seldom occurs. The headache becomes very severe and the pationt suffers from insomnia for the first few nights, but when once the headache is relieved sleep returns. There is constipation and the tongue is coated with a yellowish-brown fur except the tips and edges, which are clean. The temperature varies considerably with the severity of the case, but is generally $101^{\circ}$ to $102^{\circ}$, or even higher at nights, and $99^{\circ}$ to $101^{\circ}$ in the morning. There is generally defervescence, the fever lasting about twelve days.

The pulse-rate is slow in com. parison with the temperature. This is a very diagnostic sign, and often gives one a clue to the real nature of the disease during the first few days. The pulse-rate is often described as being rapid in this disease, but careful observation of my own cases and a study of a large number of charts from various stations in India entirely disproves this. ${ }^{1}$

In a few cases there is initial bronchitis or tonsillitis, and epistaxis sometimes occurs.

A rash may be present during the first few days, bit 